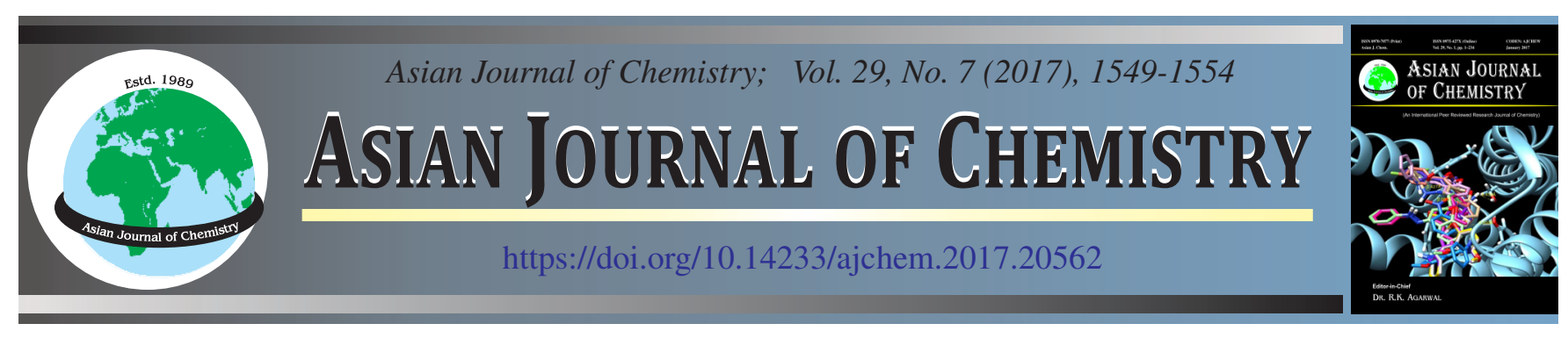

\title{
Bioactive Formylpyrazole Analogues: Synthesis, Antimicrobial, Antioxidant and Molecular Docking Studies
}

\author{
Pavithra Gurunanjappa ${ }^{1}$, Vivek Hamse Kameshwar ${ }^{2}$ and Ajay Kumar Kariyappa ${ }^{1, *}$
}

${ }^{1}$ Department of Chemistry, Yuvaraja's College, Mysuru-570 005, India

${ }^{2}$ Department of Biotechnology, Sri Jayachamarajendra College of Engineering, Mysuru-570 006, India

*Corresponding author: E-mail: ajaykumar@ycm.uni-mysore.ac.in

\section{INTRODUCTION}

The emergence of new infectious diseases and increasing resistance of microorganisms is the major cause of morbidity and mortality [1]. Excessive ROS produced by the human bodies result in the damage to various cell constituents that lead to serious health problems, which were overcome by antioxidants [2]. Among the nitrogen heterocycles, pyrazole core occupies prime position in bioorganic chemistry for their bioactive nature. Pyrazole derivatives have played a crucial role in the field of pharmaceutical chemistry and have been extensively used as important pharmacores in drug designing. Designed series of pyrazoles exhibited a broad spectrum of biological activities, few to mention that the antiproliferative activities, anticancer and anti-inflammatory activities and antitubercular activities [3,4].

Pyrazole and its derivatives are regarded as useful synthons in organic synthesis for building bioactive molecules [5] and these have significant impact on the design and development of novel drugs [6]. Literature studies reveal that pyrazole derivatives exhibited the antioxidant [7] analgesic [8] antiviral [9] and anti-inflammatory properties [10]. In view of the broad spectrum of synthetic and biological applications of pyrazoles and in search of new potent antimicrobial and antioxidant agents, we herein report the results of the synthesis of a series of formylpyrazole derivatives and their antimicrobial, antioxidant activities and molecular docking studies.

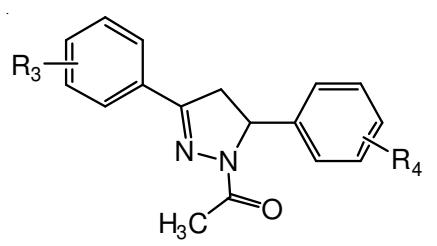

(i)<smiles>Nc1ccc(Cl)cc1C1=NN(C(=O)C2CC2)CC1</smiles>

(ii)<smiles>[R]c1ccc(C2CC(c3ccccc3)=NN2C(=S)Nc2ccccc2)cc1</smiles>

Formylpyrazole derivative

\section{EXPERIMENTAL}

Reagents and chemicals used were procured from commercial sources (Merck Chemicals, India; Aldrich, India) and used without any further purification. Melting points were determined by an open capillaries tube method and are uncorrected. ${ }^{1} \mathrm{H}$ NMR and ${ }^{13} \mathrm{C}$ NMR spectra obtained using an Agilent (400 MHz) and (100 MHz) NMR spectrometer, respectively using $\mathrm{CDCl}_{3}$ as solvent. Mass spectra were obtained on Mass Lynx SCN781 spectrometer in TOF mode. The elemental analyses were done using a Thermo Finnigan Flash EA 1112 CHNS analyzer. Thin layer chromatography (TLC) was carried 
out on aluminum sheets coated in Merck Kieselgel silica gel 60 , eluting with ethyl acetate: hexane $(1: 4 \mathrm{v} / \mathrm{v})$. The spots were visualized under UV light.

2-Acetyl-1-hydroxy naphthol (1) reacted with phenylhydrazine hydrochlorides, $\mathbf{2}(\mathbf{a}-\mathbf{f})$ in the presence of sodium acetate to produce hydrazones, $3(\mathbf{a}-\mathbf{f})$. Compounds, $3(\mathbf{a}-\mathbf{f})$ yielded formylpyrazoles, $\mathbf{4}(\mathbf{a}-\mathbf{f})$ in good yields by VilsmeierHack reaction (Fig. 1).

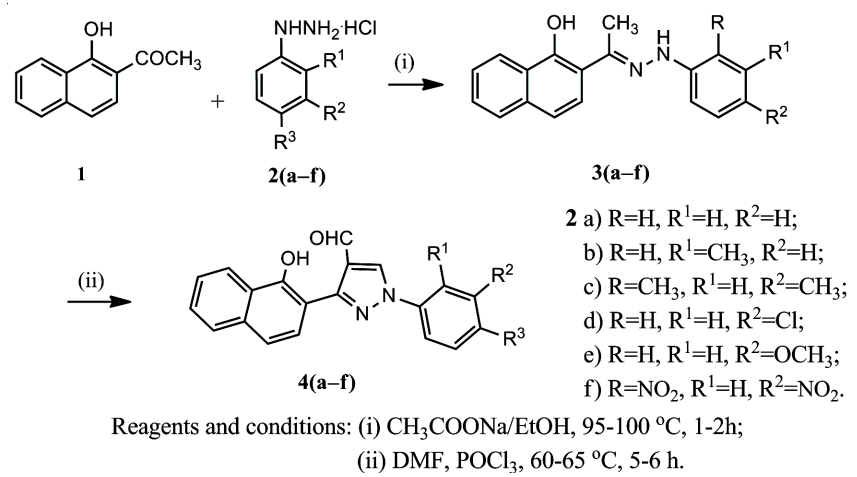

Fig. 1. Reaction path for synthesis of formylpyrazoles $\mathbf{4}(\mathbf{a}-\mathbf{f})$

Synthesis of hydrazones 3(a-f): A series of new hydrazones were synthesized by a known procedure [11], 1-(1-hydroxynaphthalen-2-yl)ethanone (1) $(0.001 \mathrm{~mol})$ in $15 \mathrm{~mL}$ ethyl alcohol was added to a solution of phenylhydrazine hydrochlorides $2(\mathbf{a}-\mathbf{f})(0.001 \mathrm{~mol})$ and sodium acetate $(0.01 \mathrm{~mol})$ in water and the mixture was heated at $90-95^{\circ} \mathrm{C}$ for $3 \mathrm{~h}$. After completion of reaction, it was allowed to cool to room temperature, precipitated hydrazones were collected and purified by crystallization from methanol to give the compounds $\mathbf{3}(\mathbf{a}-\mathbf{f})$.

2-[1-(2-Phenylhydrazono)ethyl]naphthalen-1-ol (3a): Yield $90 \%$, m.p. $162-163{ }^{\circ} \mathrm{C} ;{ }^{1} \mathrm{H}$ NMR: 10.108 (s, $\left.1 \mathrm{H}, \mathrm{OH}\right)$, 8.112 (s, 1H, NH), 6.213-7.712 (m, 11H, Ar-H), 3.108 (s, 3H, $\left.\mathrm{CH}_{3}\right), 1.932\left(\mathrm{~s}, 3 \mathrm{H}, \mathrm{CH}_{3}\right)$.

2-[1-(2-(m-Tolyl)hydrazono)ethyl]naphthalen-1-ol (3b): Yield $76 \%$, m.p. $154-155{ }^{\circ} \mathrm{C}$; ${ }^{1} \mathrm{H}$ NMR: 10.113 (s, 1H, $\mathrm{OH}), 8.512$ (s, 1H, NH), 6.910-8.128 (m, 10H, Ar-H), 3.108 (s, 3H, $\left.\mathrm{CH}_{3}\right), 2.326\left(\mathrm{~s}, 3 \mathrm{H}, \mathrm{CH}_{3}\right)$.

2-[1-(2-(2,4-Dimethylphenyl)hydrazono)ethyl]naphthalen-1-ol (3c): Yield $85 \%$, m.p. $160-161{ }^{\circ} \mathrm{C}$; ${ }^{1} \mathrm{H}$ NMR: 10.096 (s, 1H, OH), 8.586 (s, 1H, NH), 6.986-8.110 (m, 9H, Ar-H), 3.008 (s, 3H, $\left.\mathrm{CH}_{3}\right), 2.330\left(\mathrm{~s}, 6 \mathrm{H}, \mathrm{CH}_{3}\right)$.

2-[1-(2-(4-Chlorophenyl)hydrazono)ethyl]naphthalen1-ol (3d) [11]: Yield $82 \%$, m.p. 174- $175{ }^{\circ} \mathrm{C} ;{ }^{1} \mathrm{H}$ NMR: 10.121 (s, 1H, OH), 8.482 (s, 1H, NH), 7.026-8.412 (m, 10H, Ar-H), $2.382\left(\mathrm{~s}, 3 \mathrm{H}, \mathrm{CH}_{3}\right)$.

2-[1-(2-(4-Methoxyphenyl)hydrazono)ethyl]naphthalen1-ol (3e): Yield $78 \%$, m.p. $168-170{ }^{\circ} \mathrm{C}$; ${ }^{1} \mathrm{H}$ NMR: 10.116 (s, $1 \mathrm{H}, \mathrm{OH}), 8.522$ (s, 1H, NH), 7.246-8.186 (m, 10H, Ar-H), $3.848\left(\mathrm{~s}, 3 \mathrm{H}, \mathrm{OCH}_{3}\right), 2.980\left(\mathrm{~s}, 3 \mathrm{H}, \mathrm{CH}_{3}\right)$.

2-[1-(2-(2,4-Dinitrophenyl)hydrazono)ethyl]naphthalen1-ol (3f): Yield $83 \%$, m.p. $210-211{ }^{\circ} \mathrm{C} ;{ }^{1} \mathrm{H}$ NMR: 10.230 (s, $1 \mathrm{H}, \mathrm{OH}), 8.543$ (s, 1H, NH), 7.556-8.236 (m, 9H, Ar-H), 2.982 (s, $3 \mathrm{H}, \mathrm{CH}_{3}$ ).

Synthesis of 3-(1-hydroxynaphthalen-2-yl)-1-aryl-1Hpyrazole-4-carbaldehydes 4(a-f). Drop-wise addition of $\mathrm{POCl}_{3}$ $(1.2 \mathrm{~mL})$ to a cold DMF $(10 \mathrm{~mL})$ in a reaction flask produces
Vilsmeier-Haack reagent, a solution of hydrazones (3a-f) $(0.001 \mathrm{~mol})$ in $5 \mathrm{~mL} \mathrm{DMF}$ was added to it and the mixture was stirred for $6 \mathrm{~h}$ at $60-65^{\circ} \mathrm{C}$. The progress of the reaction was monitored by TLC. After completion, the mixture was poured into ice cold water and then neutralized with $\mathrm{NaHCO}_{3}$. The precipitated products were collected and purified by crystallization from methanol to give compounds $\mathbf{4}(\mathbf{a}-\mathbf{f})$.

3-(1-Hydroxynaphthalen-2-yl)-1-phenyl-1H-pyrazole4-carbaldehyde (4a): Yield $86 \%$, m.p. 147-148 ${ }^{\circ} \mathrm{C}$; IR: 3228, $1668 \mathrm{~cm}^{-1}$; ${ }^{1} \mathrm{H}$ NMR: 11.125 (s, 1H, CHO), 10.263 (s, 1H, $\mathrm{OH}), 8.574$ (s, 1H, pyrazole-H), 7.412-8.438 (m, 11H, Ar-H); ${ }^{13} \mathrm{C}$ NMR: 119.3 (1C), 119.5 (3C), 123.3 (2C), 125.5 (1C), 125.8 (2C), 127.3 (1C), 127.5 (2C), 128.4 (2C), 129.9 (3C), 132.6 (1C), 153.0 (1C), 184.31(1C); MS m/z: $314\left(\mathrm{M}^{+}\right), 313$ (M-1, $100 \%$ ); Anal. calcd. for $\mathrm{C}_{20} \mathrm{H}_{14} \mathrm{~N}_{2} \mathrm{O}_{2} \%$ : C, 76.42; $\mathrm{H}$, 4.49; N, 8.91; Found: C, 76.71; H, 4.24; N, 8.68.

3-(1-Hydroxynaphthalen-2-yl)-1-(3-methylphenyl)1H-pyrazole-4-carbaldehyde (4b): Yield $80 \%$, m.p. 136$137{ }^{\circ} \mathrm{C}$; IR: 3247, $1662 \mathrm{~cm}^{-1}$; ${ }^{1} \mathrm{H}$ NMR: 11.092 (s, 1H, CHO), 10.268 (s, 1H, OH), 8.711 (s, 1H, pyrazole-H), 7.721-8.506 (m, 10H, Ar-H), 1.243 (s, 3H, $\mathrm{CH}_{3}$ ); ${ }^{13} \mathrm{C} \mathrm{NMR}: 22.3$ (1C), 117.2 (2C), 119.7 (1C), 123.6 (2C), 124.4 (1C), 126.7 (1C), 127.1 (2C), 127.5 (1C), 127.9 (2C), 128.1 (1C), 128.6 (1C), 129.4 (2C), 132.7 (1C), 134.5 (1C), 152.1 (1C), 183.1 (1C); MS m/z: $329\left(\mathrm{MH}^{+}\right)$; Anal. calcd. for $\mathrm{C}_{21} \mathrm{H}_{16} \mathrm{~N}_{2} \mathrm{O}_{2} \%$ : C, 76.81; $\mathrm{H}, 4.91$; N, 8.53; Found: C, 76.59; H, 4.63; N, 8.87.

3-(1-Hydroxynaphthalen-2-yl)-1-(2,4-dimethylphenyl)1H-pyrazole-4-carbaldehyde (4c): Yield 85\%, m.p. 140-141 ${ }^{\circ} \mathrm{C}$; IR: 3247, $1665 \mathrm{~cm}^{-1}$; ${ }^{1} \mathrm{H}$ NMR: 11.011 (s, 1H, CHO), 10.275 (s, 1H, OH), 8.699 (s, 1H, pyrazole-H), 7.696-8.495 (m, 9H, Ar-H), 2.134 (s, 6H, $\left.\mathrm{CH}_{3}\right),{ }^{13} \mathrm{C} \mathrm{NMR}\left(\mathrm{CDCl}_{3}, 100 \mathrm{MHz}\right)$

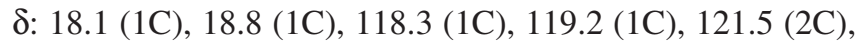
$122.4(1 \mathrm{C}), 124.1$ (1C), $124.5(2 \mathrm{C}), 125.2(3 \mathrm{C}), 127.5(1 \mathrm{C}), 127.6$ (1C), 128.4 (1C), 131.2 (3C), 134.5 (1C), 152.1 (1C), 181.3 (1C); $\mathrm{MS} \mathrm{m} / z$ : $343\left(\mathrm{MH}^{+}\right)$; Anal. calcd. for $\mathrm{C}_{22} \mathrm{H}_{18} \mathrm{~N}_{2} \mathrm{O}_{2} \%$ : C, 77.17; H, 5.30; N, 8.18; Found: C, 77.35; H, 5.14; N, 8.36.

1-(4-Chlorophenyl)-3-(1-hydroxynaphthalen-2-yl)-1Hpyrazole-4-carbaldehyde (4d): Yield $81 \%$, m.p. $180-182{ }^{\circ} \mathrm{C}$; IR: 3215, $1681 \mathrm{~cm}^{-1}$; ${ }^{1} \mathrm{H}$ NMR: 11.103 (s, 1H, CHO), 10.274 (s, 1H, OH), 8.569 (s, 1H, pyrazole-H), 7.486-8.328 (m, 10H, $\mathrm{Ar}-\mathrm{H}) ;{ }^{13} \mathrm{C} \mathrm{NMR}\left(\mathrm{CDCl}_{3}, 100 \mathrm{MHz}\right) \delta: 116.4$ (1C), 118.7 (1C), 121.5 (2C), 122.4 (2C), 124.5 (1C), 126.1 (2C), 126.9 (1C), 127.5 (1C), 130.1 (2C), 131.2 (1C), 132.4 (1C), 132.9 (1C), 135.5 (2C), 154.8 (1C), 180.1 (1C); MS m/z: $349\left(\mathrm{MH}^{+},{ }^{35} \mathrm{Cl}\right)$, $351\left(\mathrm{MH}^{+}+2,{ }^{37} \mathrm{Cl}\right)$; Anal. calcd. for $\mathrm{C}_{20} \mathrm{H}_{13} \mathrm{ClN}_{2} \mathrm{O}_{2} \%$ : C, 68.87; H, 3.76; N, 8.03; Found: C, 68.61; H, 3.91; N, 8.28.

3-(1-Hydroxynaphthalen-2-yl)-1-(4-methoxyphenyl)1H-pyrazole-4-carbaldehyde (4e): Yield 86\%, m.p. 155-157 ${ }^{\circ} \mathrm{C}$; IR: 3232, $1675 \mathrm{~cm}^{-1}$; ${ }^{1} \mathrm{H}$ NMR: 11.017 (s, 1H, CHO), 10.279 (s, 1H, OH), 8.592 (s, 1H, pyrazole-H), 7.387-8.463 (m, 10H, Ar-H), 3.128 (s, 3H, $\left.\mathrm{OCH}_{3}\right) ;{ }^{13} \mathrm{C}$ NMR: 55.1 (1C), 116.2 (2C), 117.5 (1C), 119.2 (1C), 121.1 (1C), 122.4 (2C), 125.1 (1C), 126.8 (2C), 127.1 (1C), 127.8 (2C), 129.8 (1C), 132.9 (2C), 133.2 (1C), 152.4 (1C), 154.5 (1C), 183.2 (1C); MS m/z: $345\left(\mathrm{MH}^{+}\right)$; Anal. calcd. for $\mathrm{C}_{21} \mathrm{H}_{16} \mathrm{~N}_{2} \mathrm{O}_{3} \%$ : C, 73.24; H, 4.68; N, 8.13; Found: C, 73.57; H, 4.42; N, 8.36.

3-(1-Hydroxynaphthalen-2-yl)-1-(2,4-dinitrophenyl)$1 \boldsymbol{H}$-pyrazole-4-carbaldehyde (4f): Yield 80 \%, m.p. 198-199 
${ }^{\circ} \mathrm{C}$; IR: 3243, $1678 \mathrm{~cm}^{-1}$; ${ }^{1} \mathrm{H}$ NMR: 11.115 (s, 1H, CHO), 10.271 (s, 1H, OH), 8.594 (s, 1H, pyrazole-H), 7.439-8.573 (m, 9H, Ar-H). ${ }^{13} \mathrm{C}$ NMR: 116.1 (1C), 119.6 (1C), 120.8 (1C), 120.6 (1C), 121.8 (2C), 123.7 (1C), 125.2 (2C), 126.5 (1C), 127.1 (2C), 129.2 (1C), 134.1 (1C), 134.6 (1C), 136.2 (1C), 137.2 (1C), 142.5 (1C), 152.1 (1C), 182.3 (1C); MS m/z: 345 $\left(\mathrm{MH}^{+}\right)$; Anal. calcd. for $\mathrm{C}_{21} \mathrm{H}_{16} \mathrm{~N}_{2} \mathrm{O}_{3} \%: \mathrm{C}, 73.24 ; \mathrm{H}, 4.68 ; \mathrm{N}$, 8.13; Found: C, 73.52; H, 4.42; N, 8.35.

Antimicrobial activity: Antimicrobial activities of the synthesized compounds were determined as minimum inhibitory concentrations (MIC's) by broth dilution technique [7]. The nutrient broth, which contains logarithmic serially twofold diluted amount of compounds $3(\mathbf{a}-\mathbf{f})$ and $\mathbf{4}(\mathbf{a}-\mathbf{f})$ and control was inoculated with approximately $5 \times 10^{5}$ cfu of actively dividing bacteria cells. The cultures were incubated for $24 \mathrm{~h}$ at $37^{\circ} \mathrm{C}$ for bacterial and $72 \mathrm{~h}$ at $37^{\circ} \mathrm{C}$ for fungal stains and the growth was monitored visually. The tests were conducted in triplicates against bacterial pathogens Escherichia coli, Pseudomonas aeruginosa, Staphylococcus aureus and against fungal stains Aspergillus nigar, Aspergillus flavus and Candila albicans. Ciprofloxacin and nystatin were used as positive controls against bacterial and fungal species, respectively; methanol was used as solvent control. The results are expressed as a mean \pm standard deviation (SD) (Table-1).

DPPH radical scavenging assay: 1,1-Diphenylpicrylhydrazyl (DPPH) radical scavenging ability of the $\mathbf{3}(\mathbf{a}-\mathbf{f})$ and 4(a-f) was performed by Blois method [12,13]. $1 \mathrm{~mL}$ of DPPH solution $(0.1 \mathrm{mM}$ in $95 \%$ methanol) was mixed with different aliquots of test samples $(25,50,75$ and $100 \mu \mathrm{g} / \mathrm{mL})$ in methanol.
The mixture was shaken vigorously and allowed to stand for $20 \mathrm{~min}$ at room temperature. The absorbance was read against blank at $517 \mathrm{~nm}$ in an ELICO SL $159 \mathrm{UV}$-visible spectrophotometer. The free radical scavenging potential was calculated as a percentage (I \%) of DPPH decolouration using the equation:

$$
\mathrm{I}(\%) \text { of scavenging }=\frac{\mathrm{A}_{0}-\mathrm{A}_{1}}{\mathrm{~A}_{0}} \times 100
$$

$\mathrm{A}_{0}$ is the absorbance of the control without test compounds; $\mathrm{A}_{1}$ is the absorbance of test compounds. The experiments were performed in triplicate; the results were expressed as a mean \pm standard deviation (SD) (Table-2).

Hydroxyl radical scavenging assay: Hydoxyl radical scavenging ability of compounds $\mathbf{3}(\mathbf{a}-\mathbf{f})$ and $\mathbf{4}(\mathbf{a}-\mathbf{f})$ was performed by known method [14]. Mixture of phosphate buffer $(0.1$ $\mathrm{mL}), 2$-deoxyribose $(0.2 \mathrm{~mL})$, test solution $(25,50,75$ and $100 \mu \mathrm{g} / \mathrm{mL}), \mathrm{H}_{2} \mathrm{O}_{2}((0.1 \mathrm{~mL}, 10 \mathrm{mM})$, ascorbic acid $((0.1 \mathrm{~mL}$, $1 \mathrm{mM})$, EDTA $(0.1 \mathrm{~mL})$ and $\mathrm{FeCl}_{3}((0.01 \mathrm{~mL}, 100 \mathrm{mM})$ was incubated at $37^{\circ} \mathrm{C}$ for $60 \mathrm{~min}$. Thereafter, the reaction was arrested by adding cold trichlroacetic acid ( $1 \mathrm{~mL}, 2.8 \%)$ and thiobarbituric acid $(1 \mathrm{~mL}, 1 \%$ in $0.05 \mathrm{~N} \mathrm{NaOH})$ in boiling water for $15 \mathrm{~min}$ and, absorbance was measured at $535 \mathrm{~nm}$. Butylated hydroxyanisole (BHA) was used as positive control. Experiments were performed in triplicates and results are expressed as I \% \pm standard deviations (Table-3).

Molecular docking studies: The co-ordinates of superoxide dismutase (SOD), catalase (CAT), oxidoreductase (OXD) and tyrosinase (TYr) from Bacillus megaterium were retrieved from Brookhaven Protein Data Bank, with those PDB id's are 1CB4,

TABLE-1

MINIMUM INHIBITORY CONCENTRATION (MIC's) OF COMPOUNDS 3(a-f) AND 4(a-f) $\left(\mu \mathrm{g} / \mathrm{mL}^{*}\right)$

\begin{tabular}{|c|c|c|c|c|c|c|}
\hline Compound & S. aureus & E. coli & P. aeruginosa & A. niger & A. flavus & C. albicans \\
\hline $\mathbf{3 a}$ & $50 \pm 0.35$ & $50 \pm 0.17$ & $50 \pm 0.05$ & $50 \pm 0.50$ & $25 \pm 0.50$ & $50 \pm 0.30$ \\
\hline $\mathbf{3 b}$ & $50 \pm 0.15$ & $25 \pm 0.11$ & $12.5 \pm 0.15$ & $25 \pm 0.21$ & $50 \pm 0.26$ & $50 \pm 0.32$ \\
\hline $3 c$ & $25 \pm 0.66$ & $12.5 \pm 0.51$ & $12.5 \pm 0.20$ & $12.5 \pm 0.61$ & $50 \pm 0.36$ & $50 \pm 0.56$ \\
\hline 3d & $50 \pm 0.36$ & $50 \pm 0.25$ & $25 \pm 0.26$ & $50 \pm 0.57$ & $25 \pm 0.75$ & $75 \pm 0.42$ \\
\hline $3 e$ & $75 \pm 0.20$ & $100 \pm 0.45$ & $50 \pm 0.40$ & $75 \pm 0.65$ & $100 \pm 1.06$ & $50 \pm 0.72$ \\
\hline $3 f$ & $100 \pm 0.25$ & $50 \pm 0.26$ & $50 \pm 0.25$ & $50 \pm 0.50$ & $50 \pm 0.65$ & $100 \pm 0.60$ \\
\hline $4 a$ & $50 \pm 0.26$ & $25 \pm 0.30$ & $25 \pm 0.30$ & $50 \pm 0.56$ & $50 \pm 0.36$ & $50 \pm 0.55$ \\
\hline $4 c$ & $12.5 \pm 0.30$ & $12.5 \pm 0.47$ & $25 \pm 0.30$ & $12.5 \pm 0.60$ & $25 \pm 0.76$ & $50 \pm 0.75$ \\
\hline $4 d$ & $100 \pm 0.36$ & $50 \pm 0.32$ & $75 \pm 0.15$ & $50 \pm 0.82$ & $75 \pm 0.72$ & $50 \pm 0.36$ \\
\hline $4 e$ & $25 \pm 0.30$ & $6.25 \pm 0.45$ & $12.5 \pm 0.41$ & $25 \pm 0.57$ & $12.5 \pm 0.62$ & $25 \pm 0.60$ \\
\hline $4 f$ & $50 \pm 0.15$ & $75 \pm 0.30$ & $50 \pm 0.45$ & $75 \pm 0.56$ & $50 \pm 0.60$ & $75 \pm 0.71$ \\
\hline Ciprofloxacin & $25 \pm 0.40$ & $25 \pm 0.30$ & $12.5 \pm 0.26$ & - & - & - \\
\hline Nystatin & - & - & - & $25 \pm 0.25$ & $25 \pm 0.21$ & $50 \pm 0.96$ \\
\hline
\end{tabular}

TABLE-2

DPPH RADICAL SCAVENGING ACTIVITY OF COMPOUNDS $4(\mathbf{a}-\mathbf{f})$ AT DIFFERENT CONCENTRATIONS IN METHANOL (MEASURED IN \%)*

\begin{tabular}{|c|c|c|c|c|}
\hline Compounds & $25(\mu \mathrm{g} / \mathrm{mL})$ & $50(\mu \mathrm{g} / \mathrm{mL})$ & $75(\mu \mathrm{g} / \mathrm{mL})$ & $100(\mu \mathrm{g} / \mathrm{mL})$ \\
\hline $4 a$ & $26.98 \pm 0.66$ & $33.43 \pm 0.60$ & $37.25 \pm 0.54$ & $46.54 \pm 0.90$ \\
\hline $4 b$ & $26.91 \pm 0.20$ & $31.88 \pm 1.39$ & $36.53 \pm 1.04$ & $47.41 \pm 0.72$ \\
\hline $4 c$ & $23.65 \pm 0.49$ & $29.95 \pm 0.95$ & $32.76 \pm 0.60$ & $39.87 \pm 0.62$ \\
\hline 4d & $21.02 \pm 0.40$ & $28.76 \pm 0.82$ & $32.43 \pm 0.58$ & $36.43 \pm 0.55$ \\
\hline $4 e$ & $31.19 \pm 0.68$ & $37.02 \pm 0.49$ & $43.96 \pm 0.49$ & $49.45 \pm 0.67$ \\
\hline $4 f$ & $20.32 \pm 0.90$ & $25.84 \pm 0.90$ & $30.71 \pm 0.60$ & $34.18 \pm 0.71$ \\
\hline Ascorbic acid ${ }^{a}$ & $26.87 \pm 0.24$ & $31.54 \pm 0.68$ & $36.09 \pm 1.22$ & $45.32 \pm 0.70$ \\
\hline
\end{tabular}

*Values are mean \pm SD of three replicates; ${ }^{a}$ Used as positive control 
TABLE-3

HYDROXYL RADICAL SCAVENGING ACTIVITY OF COMPOUNDS 4(a-f) AT DIFFERENT CONCENTRATIONS IN METHANOL (MEASURED IN \%)*

\begin{tabular}{cccc}
\hline Compounds & $25(\mu \mathrm{g} / \mathrm{mL})$ & $50(\mu \mathrm{g} / \mathrm{mL})$ & $75(\mu \mathrm{g} / \mathrm{mL})$ \\
\hline $\mathbf{4 a}$ & $8.04 \pm 0.65$ & $13.43 \pm 0.98$ & $23.13 \pm 0.88$ \\
$\mathbf{4 b}$ & $9.13 \pm 0.80$ & $13.96 \pm 1.06$ & $24.85 \pm 0.89$ \\
$\mathbf{4 c}$ & $6.87 \pm 0.39$ & $11.96 \pm 0.85$ & $22.04 \pm 0.47$ \\
$\mathbf{4 d}$ & $4.87 \pm 0.92$ & $9.76 \pm 0.32$ & $17.53 \pm 0.71$ \\
$\mathbf{4 e}$ & $11.43 \pm 0.77$ & $15.12 \pm 0.23$ & $27.81 \pm 0.78$ \\
$\mathbf{4 f}$ & $4.92 \pm 0.95$ & $10.75 \pm 0.56$ & $15.76 \pm 0.74$ \\
Butylated hydroxyanisole ${ }^{\mathrm{b}}$ & $7.11 \pm 0.24$ & $12.98 \pm 0.38$ & $22.69 \pm 0.36$ \\
\hline * Values are mean \pm SD of three replicates; ${ }^{\text {b }}$ Used as positive control
\end{tabular}

2CAG, 1MBT and 3NM8, respectively. Compounds were drawn using Maestro 2D sketcher and energy to minimize was computed by OPLS 2005. Proteins prepared by retrieving into Maestro 9.3 platform (Schrödinger, Inc.) and their structures were corrected by Prime software module of Schrödinger. Water molecules which are from SOD, CAT, OXD and TYr were removed beyond $5 \AA$ from the hetero atom. Water molecules are important in aiding the interaction between the receptor and ligands was optimized during protein pepwizard. Necessary bonds, bond orders, hybridization, explicit hydrogens and charges were automated. OPLS 2005 force field applied to the protein to restrained minimization and RMSD of $0.30 \AA$ was set to converge heavy atoms during the pre-processing of protein before starting docking. Using Extra-precision (XP) docking and scoring, each compound was docked into the receptor grid of radii $20 \AA$ and docking calculation were a judge based on the Glide score.

\section{RESULTS AND DISCUSSION}

Elucidation of structure of the synthesized compounds were obtained by ${ }^{1} \mathrm{H}$ NMR, ${ }^{13} \mathrm{C}$ NMR, Mass spectral studies and elemental analyses. Compounds $\mathbf{4}(\mathbf{a}-\mathbf{f})$ showed sharp and strong absorption bands at $1671-1662 \mathrm{~cm}^{-1}$ due to $\mathrm{C}=\mathrm{O}$ str. and broad bands at $3247-3215 \mathrm{~cm}^{-1}$ due to O-H str. in their IR spectra. In ${ }^{1} \mathrm{H}$ NMR spectra, $4(\mathbf{a}-\mathbf{f})$ showed a singlet at $\delta$ $11.092-11.125 \mathrm{ppm}$ for -CHO proton, singlet at $\delta 10.263-$ $10.279 \mathrm{ppm}$ for phenolic -OH proton, absence of signals due to $-\mathrm{NH}$ proton of its precursor $\mathbf{3}(\mathbf{a}-\mathbf{f})$ confirms the structure. In ${ }^{13} \mathrm{C}$ NMR spectra, signals obtained at $\delta 180.1-184.3 \mathrm{ppm}, \delta$ $133.2-134.5 \mathrm{ppm}, \delta 116.4-119.7 \mathrm{ppm}$ and $\delta 129.4-135.5 \mathrm{ppm}$ were due to - $\mathrm{CHO}$ carbon, newly formed pyrazole ring $\mathrm{C}-3$, C-4 and C-5 carbons, respectively. All compounds showed $\mathrm{M}+1$ ion molecular mass peak as a base peak. Further, all synthesized compounds showed satisfactory CHN analysis data when compared with the theoretically calculated values.

The preliminary studies show that all the compounds possess moderate to good bacterial inhibition. Among series, good activity was observed for compounds (3c) against $E$. coli and A. niger; (3e) against E. coli, A. flavus and C. albicans. Moderate inhibition was shown by compounds; (3a) and (4c) against $A$. flavus and $C$. albicans; (4b) against $S$. aureus and E. coli; (4a) and (4c) against $A$. flavus and C. albicans; (3b), (4e) against $P$. aeruginosa and $A$. niger; and (3b), (4a) against E. coli and $C$. albicans; and (3c) against $S$. aureus and $P$. aeruginosa organisms. Compounds (3e) and (4f) showed lesser activity against all the test strains.
Preliminary studies show that the compounds (4a), (4b) and (4e) showed remarkable radical scavenging activity in comparison with the standard. It is anticipated that, this might be attributed to the presence of $-\mathrm{CH}_{3}$ and $-\mathrm{OCH}_{3}$ substituent. While rest of the series of compounds shows lesser activities.

Preliminary studies on hydroxyl radical scavenging activities shows that compounds (4a), (4b) and (4e) possesses promising radical scavenging activity in compared with the standard butylated hydroxyanisole.

Molecular docking has been carried out to design novel potential leads. A total of six validated potential leads are suggested from the in vitro studies. Comparative investigation is based on docking score with that of the reported inhibitors. Compounds (4d) and (4f) of parental nucleus, imparted a specific geometrical space around the $\mathrm{Cu}-\mathrm{Zn}$ binding loop. Among which activity of SOD gets exuberated during the process followed by catalase [15]. Activity of $\mathrm{Cu}-\mathrm{ZnSOD}$ has studied based on protein engineering to increase activity by modifying the electrostatic environment of the active site. Strong binding of compound at $\mathrm{Cu}-\mathrm{Zn}$ domain of SOD causes increases in antioxidant activity of SOD and reduce oxidative stress [16].

Binding modes of compound (4c) showed the better pose with docking and glide score determined and those that retain interactions with Cys55 residing at $\mathrm{Cu}-\mathrm{Zn}$ loop of the SOD. Compound (3e) showed binding with His61, His78, Lys134 (Fig. 2). Compound (3c) showed $\pi-\pi$ stacking with Phe140, His54 and hydrogen bond with water of CAT (Fig. 3A). Compounds $(\mathbf{4 a}),(\mathbf{4 c}),(\mathbf{4 d})$ and $(\mathbf{4 e})$ showed better binding with OXD (Arg327 and Ile45), SOD, CAT and TYr (Lys47B), respectively. Among them, (4c) showed binding with Cys55 resided at Zn153 of SOD (Fig. 2B); (4a) showed maximum interaction with His54, Phe140 and Tyr337 of CAT (Fig. 3B). Among all the designed series, (4d) and (4e) showed very tight binding with CAT (Fig. 5A and Fig. 5B) and tyrosinase from Bacillus megaterium, respectively (Fig. 4B).

Results of docking analyses showed that, among the designed series, compounds (4c) and (4e) have strong interaction with amino acid Tyr267A, Ala44A and Tyr267B of tyrosinase. QikProp modules provide ranges of molecular predicting properties for comparing select molecule with known drugs (17]. Therefore, it is concluded from docking studies, compounds (4a), (4b) and (4e) might act as a good antioxidant compounds and are suitable candidates to be carried forward as a potential lead for targeting various diseases affected by free radicals. 

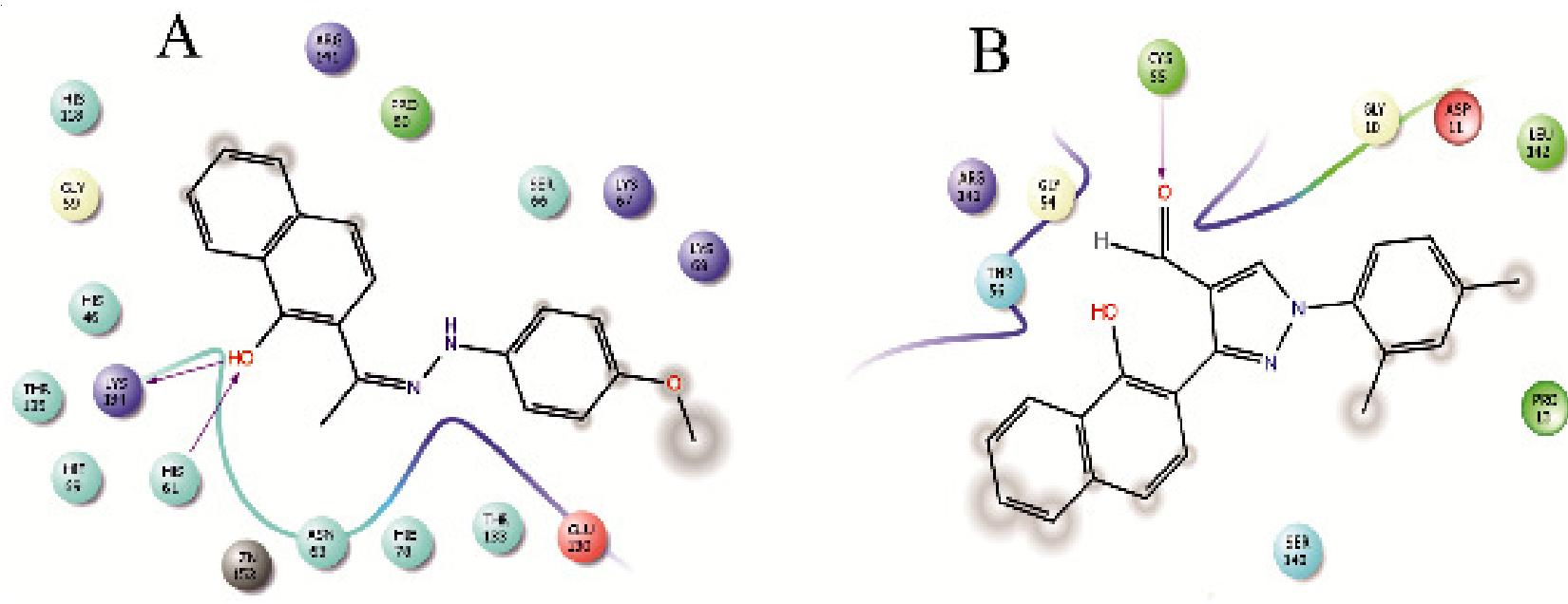

Fig. 2. Molecular interaction of SOD (PDB ID: 1CB4) with (3e) (A) and (4c) (B)

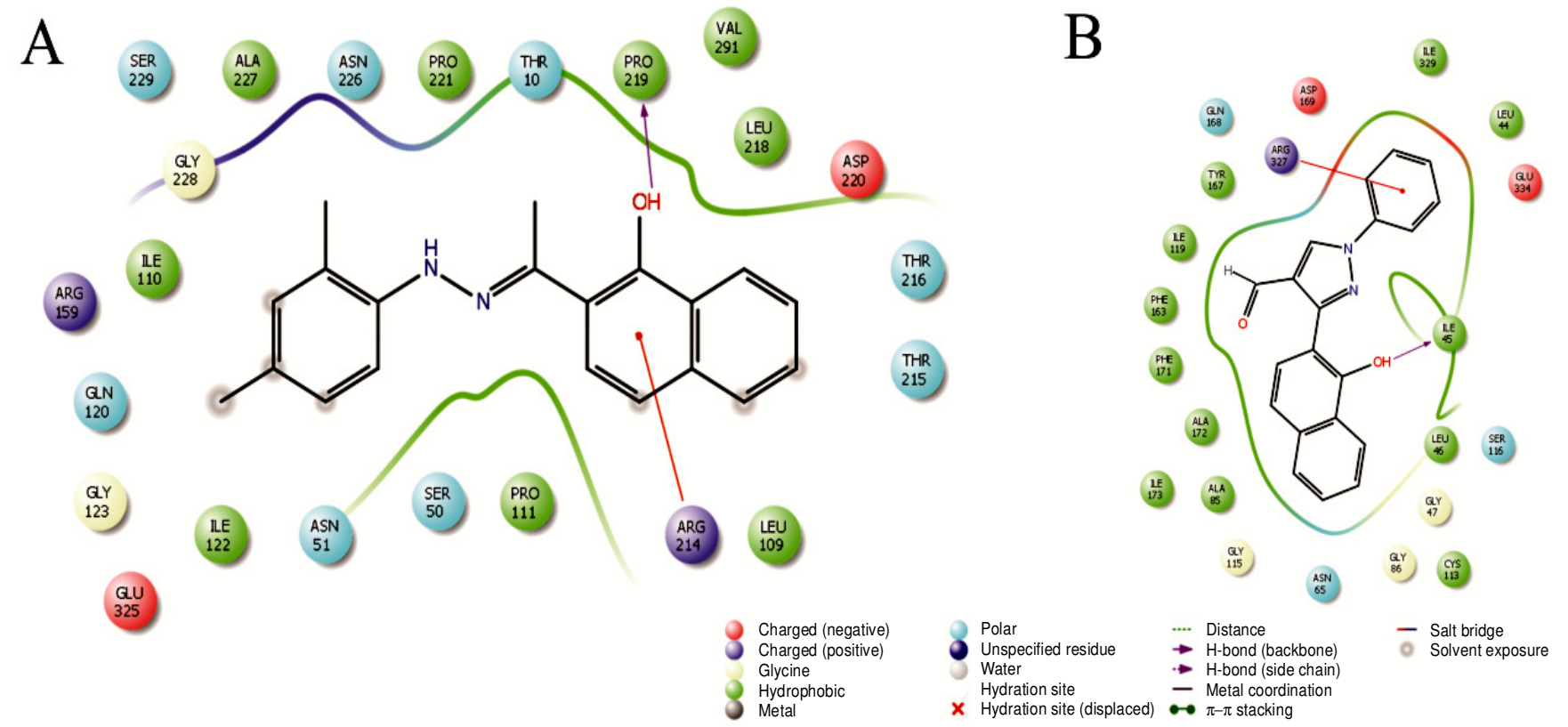

Fig. 3. Molecular interaction of catalase (PDB ID: 2CAG) with (3c) (A) and (4a) (B)
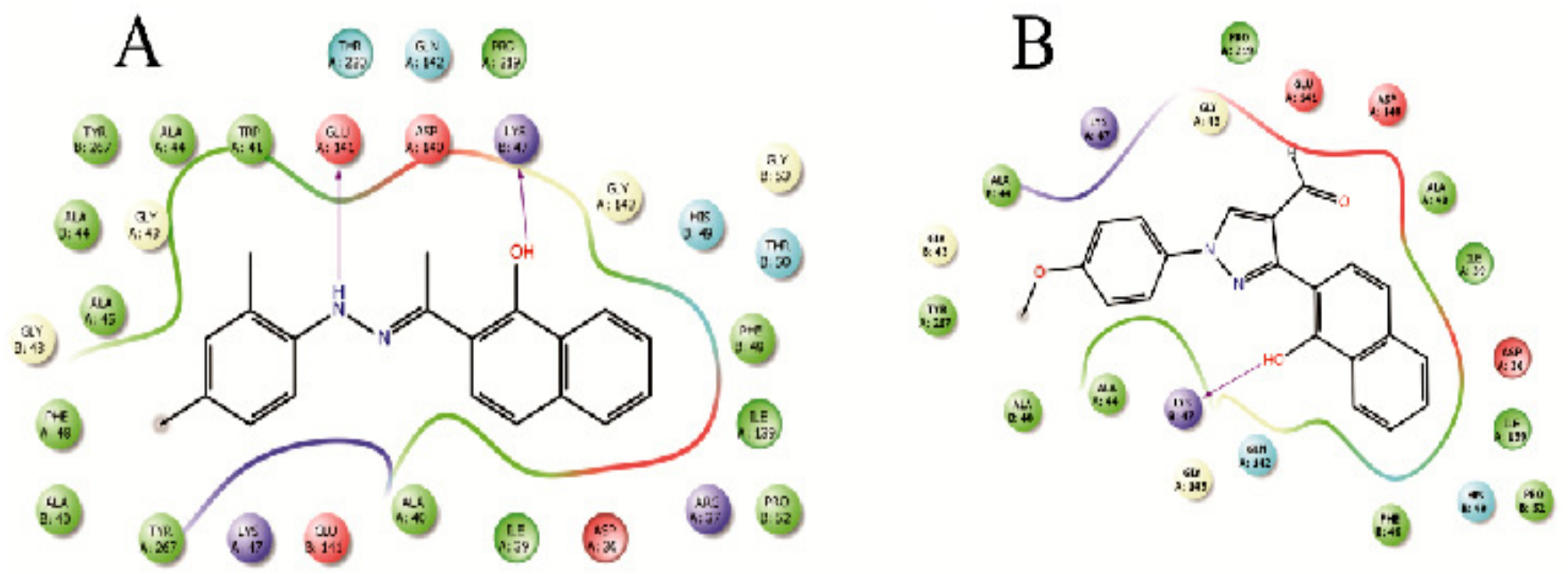

Fig. 4. Molecular interaction of tyrosinase (PDB ID: 3NM8) with (I3c) (A) and (4e) (B) 

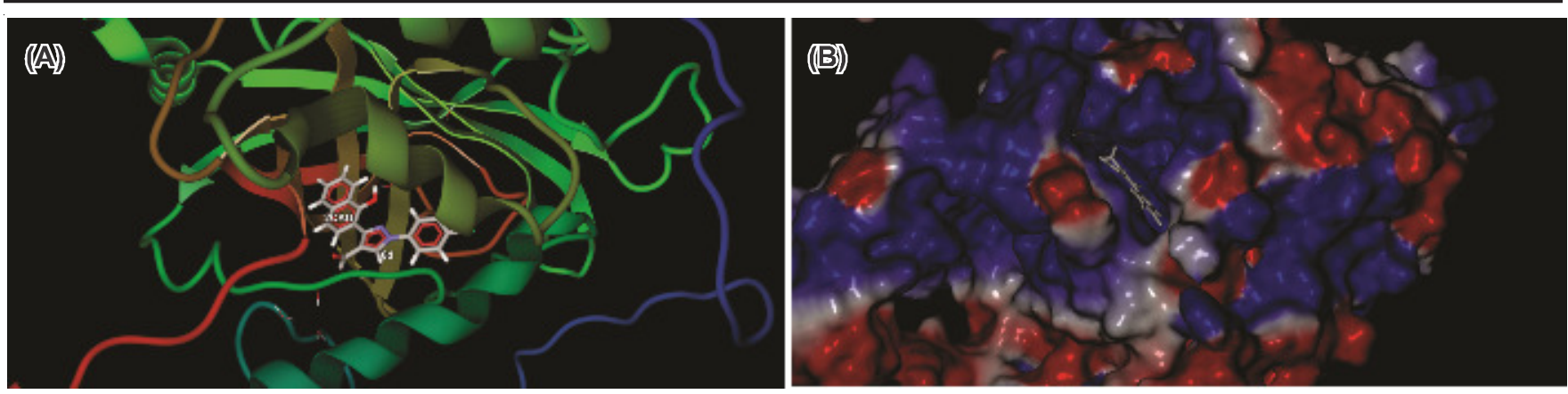

Fig. 5. Molecular secondary structure (A) and electrostatic interactions (B) of catalase with (4d)

\section{Conclusion}

The designed and synthesized series of novel formylpyrazoles were evaluated for their antimicrobial and antioxidant activities. Preliminary studies of the synthesized series, compounds (4c) and (4e) shows potent antimicrobial activities. Compounds (4a), (4b) and (4e) possess significant antioxidant activity in both DPPH and hydroxyl radical scavenging assays. In silico results are also concordant with in vitro results.

\section{ACKNOWLEDGEMENTS}

The authors acknowledge to University with Potential for Excellence (UPE) and University of Mysore for the laboratory facilities. One of the authors, G. Pavithra is grateful to the UGC for awarding NON-NET Fellowship (Order No. DV9/ 192/NON-NETFS/2013-14, Dated 11-11-2013).

\section{REFERENCES}

1. R.V. Patel, P.K. Patel, P. Kumari, D.P. Rajani and K.H. Chikhalia, Eur. J. Med. Chem., 53, 41 (2012);

https://doi.org/10.1016/j.ejmech.2012.03.033.

2. J. Boonstra and J.A. Post, Gene, 337, 1 (2004); https://doi.org/10.1016/j.gene.2004.04.032.

3. K. Ajay Kumar and M. Govindaraju, Int. J. Chemtech Res., 8, 313 (2015).

4. P. Jayaroopa, G. Vasanth Kumar, N. Renuka, M.A. Harish Nayaka and K. Ajay Kumar, Int. J. Pharmtech Res., 5, 264 (2013).

5. J. Prabhashankar, V.K. Govindappa and A.K. Kariyappa, Turk. J. Chem., 37, 853 (2013);

https://doi.org/10.3906/kim-1209-52.
6. C.V.T. Vo and J.W. Bode, J. Org. Chem., 79, 2809 (2014); https://doi.org/10.1021/jo5001252.

7. N. Renuka and K. Ajay Kumar, Bioorg. Med. Chem. Lett., 23, 6406 (2013); https://doi.org/10.1016/j.bmcl.2013.09.053.

8. A. Hall, A. Billinton, S.H. Brown, N.M. Clayton, A. Chowdhury, G.M.P. Giblin, P. Goldsmith, T.G. Hayhow, D.N. Hurst, I.R. Kilford, A. Naylor, B. Passingham and L. Winyard, Bioorg. Med. Chem. Lett., 18, 3392 (2008); https://doi.org/10.1016/j.bmcl.2008.04.018.

9. A.E. Rashad, M.I. Hegab, R.E. Abdel-Megeid, J.A. Micky and F.M. Abdel-Megeid, Bioorg. Med. Chem., 16, 7102 (2008); https://doi.org/10.1016/j.bmc.2008.06.054.

10. G. Szabo, J. Fischer, A. Kis-Varga and K. Gyires, J. Med. Chem., 51, 142 (2008); https://doi.org/10.1021/jm070821f.

11. A.L.A. Kala, K. Kumara, G. Pavithra, M. Prabhuswamy, K.A. Kumar and N.K. Lokanath, Der Pharma Chemica, 8, 328 (2016).

12. M.S. Blois, Nature, 181, 1199 (1958); https://doi.org/10.1038/1811199a0.

13. R. Nagamallu, B. Srinivasan, M.B. Ningappa and A.K. Kariyappa, Bioorg. Med. Chem. Lett., 26, 690 (2016); https://doi.org/10.1016/j.bmcl.2015.11.038.

14. P. Gurunanjappa and A.K. Kariyappa, Curr. Chem. Lett., 5, 109 (2016); https://doi.org/10.5267/j.ccl.2016.2.002.

15. K.R. Raghavendra, N. Renuka, V.H. Kameshwar, B. Srinivasan, K. Ajay Kumar and S. Shashikanth, Bioorg. Med. Chem. Lett., 26, 3621 (2016); https://doi.org/10.1016/j.bmcl.2016.06.005.

16. A.-F. Miller, Curr. Opin. Chem. Biol., 8, 162 (2004); https://doi.org/10.1016/j.cbpa.2004.02.011.

17. P.J. Hart, M.M. Balbirnie, N.L. Ogihara, A.M. Nersissian, M.S. Weiss, J.S. Valentine and D. Eisenberg, Biochem., 38, 2167 (1999); https://doi.org/10.1021/bi982284u. 